\title{
STOCHASTIC MODEL FOR THE PROCESS OF WINE AWARD: VISUALIZATION AND QUANTIFICATION
}

\section{MODELO ESTOCÁSTICO PARA O PROCESSO DE RECOMPENSA DO VINHO: VISUALIZAÇÃO E QUANTIFICAÇÃO}

\author{
José A. González ${ }^{1 *}$, Carolina M. Sánchez-Sáenz ${ }^{2}$ and Patricio Mejias-Barrera ${ }^{3}$
}

\begin{abstract}
${ }^{1}$ Department of Mathematics \& Statistics, Faculty de Natural \& Exact Sciences, University of Playa Ancha / Valparaíso, Avenue Playa Ancha 850, Valparaíso, Chile

${ }^{2}$ Department of Civil and Agricultural Engineering. School of Engineering, Universidad Nacional de Colombia, Carrera 45 N 26-85, Bogotá D.C., Colombia

${ }^{3}$ Department of Wine, Food and Molecular Biosciences, Faculty of Agriculture \& Life Sciences, Lincoln University, PO Box 84, Lincoln 7647, Canterbury, New Zealand

*Corresponding author: Tel: 56-32-2500550, fax: 56-32-2500546, e-mail: jgonzalez@upla.cl
\end{abstract}

(Received 21.07.2014. Accepted 14.11.2014)

\section{SUMMARY}

Sensory analysis is an important part of the process of evaluation of the quality of wines. Nowadays, one of the most used methods for describing this evaluation is the concept of awards. In the process of granting the award for a wine, each specialist assigns a score for the quality according to the tasting score sheet proposed by the Organisation Internationale de la Vigne et du Vin (OIV). After this, on the basis of the average of the scores assigned by each specialist, the award of the wine is determined. The present proposal seeks to refine the concept of award on the basis of the scores assigned to each item on the tasting score sheet, as well as giving theoretical support to the refinement of the award concept, identified as consistency. The defined technical support uses statistical tools for the modeling and structuring of the methodology. Finally, a method of visualizing the dynamic of the scores assigned by each specialist is presented. It is concluded that the stochastic quantification and the theory of graphs allowed the visualization and definition of a theoretical support that refines the process of the determination of wine quality.

\section{RESUMO}

Uma parte fundamental no processo da avaliação da qualidade dos vinhos é a análise sensorial. Na atualidade um dos métodos mais utilizados para descrever a avaliação é o conceito de recompensa. No processo de especificação da recompensa do vinho, o especialista atribui uma pontuação de qualidade conforme a ficha de prova gerada pela "Organisation Internationale de la Vigne et du Vin” (OIV). Subsequentemente, em função da média das pontuações geradas pelo especialista, determina-se a recompensa do vinho. Esta proposta pretendeu refinar o conceito de recompensa em função do comportamento das pontuações em cada item da ficha de prova, além de gerar o suporte teórico para um refinamento do conceito de recompensa, identificado como consistência. O suporte teórico definido utiliza ferramentas estatístico-matemáticas para a modelação e a estruturação da metodologia. Finalmente apresenta-se uma metodologia de visualização da dinâmica das pontuações atribuídas pelo especialista. Conclui-se que a quantificação estocástica e a teoria de grafos permitem a visualização e definição de um suporte teórico que refina o processo de determinação da qualidade do vinho.

Key words: tasting checklist, sensory evaluation, graphs, Poisson distribution. Palavras-chave: folha de degustação, avaliação sensorial, grafos, distribuição Poisson.

\section{INTRODUCTION}

Wine is a beverage with particular organoleptic characteristics that have been recognized all over the world. Nowadays, because of its great acceptance by consumers, it is considered one of the most highly commercialized products on the international market. As a consequence, many studies to evaluate wine quality have been developed, based on wine sensory attributes (Muroz et al., 1992; Rizzon et al., 1999, Manfroi et al., 2010).
Wine is the final product of the combination of several factors, which have been previously described as having a direct influence on its characteristics. For example, Gladstones (2011) described the importance of the grape variety, climate, topography, geology and soil, and "the human factor" (viticulture management and winemaking, mainly), as key factors to determine the characteristics of the final product.

Commonly, wine sensory evaluation is performed by a sensory panel composed by highly experienced 
people involved in the wine industry, or people who have been trained for wine evaluation. For wine sensory analysis, some methods have been described to compare the performance of the judges, with the aim of comparing individual performances (Brien et al., 1987; Lima et al., 1988; Sinesio et al., 1990; Cardinal et al., 1994; Lawless and Liu, 1997; Bi, 2003; Latreille et al., 2006). However, methodologies for a systematic evaluation of the quality of the final judgment are scarce, and many times, not practical.

Thus, Vannier et al. (1999) defined a practical framework to perform sensory measurements using the Sensory Profile Technique, which can be used for Champagne wine quality control. A comparison of methods for evaluating the performance of a trained sensory panel was researched by King et al. (2001). Gawel and Godden (2008) evaluated the consistency of wine quality assessments from expert wine tasters. These authors highlighted the variability of the results within the panel, which needs to be further investigated.

As previously described, the evaluation of the quality of a wine is carried out by specially-trained individuals through sensorial analysis, but international competitions demand even more rigorous quality standards. In this way, there is a high interest in studying new techniques that enable to determine, in a rapid and practical way, the quality of a wine. Thus, Alvelos et al. (2000) developed a statistical method for controlling wine tasting panels. Etaio et al. (2010) explained the method developed to evaluate and score the sensory quality of young red wines from Rioja Alavesa. The Organisation Internationale de la Vigne et du Vin guidelines for international wines and spirit competitions (OIV CONCOURS 332B-2009), proposed a methodology to grant awards, based on wine quality, by assigning scores to different aspects of the wine. Using this method, a wine can obtain a maximum of 100 points. The OIV tasting score sheet comprises four sections: appearance, aroma, taste, and harmony, overall judgment, which are also divided into sub-sections:

- Appearance: Limpidity; Separate aspect of limpidity

- Aroma: Genuineness; Positive intensity; Quality

- Taste: Genuineness; Positive intensity; Harmonious persistence; Quality

- Harmony: Overall judgment

Most of the terminology used by the judges to define the organoleptic characteristics of the wines, is based on specialized literature that has previously described the aroma profile (Noble et al., 1987; Jackson, 2009), taste (Gawel et al., 2000), appearance, and overall judgment (Jackson, 2009), for evaluating wine quality, which constitutes the language commonly used in the competitions.

During the competition, wines are tasted and evaluated under the conditions described in the OIV guidelines. After finishing the sensorial evaluation, the award for the different wines is obtained, allowing the identification of their level. According to the different aspects established by the OIV, the results can be divided into:

- $\quad$ Grand Gold: At least 92 points

- Gold: At least 85 points

- Silver: At least 82 points

- Bronze: At least 80 points

Although the OIV recommends to discard all the scores that differ more than seven points from the average, and to inform the panel about which method will be used beforehand, once all the results are calculated, the internal dynamic of the scores for each aspect and the standard deviation of the results have not being considered. This problem is summarized in the following simulation:

The characteristics of the tasting score sheet proposed by the OIV, and the methodology used for the evaluation, were the base to propose some changes. For this, three tasting score sheets were simulated for three wines of the same category (wines A, B, and C), based on the OIV methodology. The award level for these three wines is bronze, whose final score was 80 points for all of them. The results are shown in Table I. Importantly, the Table I is only motivational, relative to the mean.

TABLE I

Sheet corresponding to simulation of three wine tasting

Ficha correspondente à simulação da prova de três vinhos

\begin{tabular}{|c|c|c|c|c|}
\hline Dimensions & & Wine A & Wine B & Wine C \\
\hline \multirow[t]{2}{*}{ Appearance } & Limpidity & 3 & 3 & 5 \\
\hline & $\begin{array}{l}\text { Separate } \\
\text { aspect of } \\
\text { limpidity }\end{array}$ & 4 & 4 & 8 \\
\hline \multirow[t]{3}{*}{ Aroma } & Genuineness & 6 & 4 & 2 \\
\hline & $\begin{array}{l}\text { Positive } \\
\text { intensity }\end{array}$ & 8 & 6 & 2 \\
\hline & Quality & 16 & 16 & 8 \\
\hline \multirow[t]{4}{*}{ Taste } & Genuineness & 4 & 4 & 6 \\
\hline & $\begin{array}{l}\text { Positive } \\
\text { intensity }\end{array}$ & 6 & 6 & 8 \\
\hline & $\begin{array}{l}\text { Harmonious } \\
\text { persistence }\end{array}$ & 6 & 6 & 8 \\
\hline & Quality & 16 & 22 & 22 \\
\hline \multirow[t]{3}{*}{ Harmony } & $\begin{array}{l}\text { Overall } \\
\text { judgment }\end{array}$ & 11 & 9 & 11 \\
\hline & Reward level & 80 & 80 & 80 \\
\hline & $\begin{array}{l}\text { Standard } \\
\text { deviation }\end{array}$ & 4.78 & 6.2 & 5.7 \\
\hline
\end{tabular}

The methodology incorporates additional discriminative elements such as the consistency and dynamics overcoming some limitations of measures of center.

This study aims to propose a complementary method for the determination of the quality of a wine, that considers the dynamic of the interactions between the different aspects evaluated, oriented towards the 
enrichment of the analysis of the scores for each item that guarantees the refinement of the award process.

In this simulation, from the current point of view, the three wines have received the same award, identified as bronze. Yet, if the behavior of the individual aspects is analyzed, the following is seen (Table I):

For the aroma aspect, totally different results are seen, and because of that, a question is raised with respect to the assignment of quality of these wines. In particular, the results for the aroma aspect are shown in Figure 1.

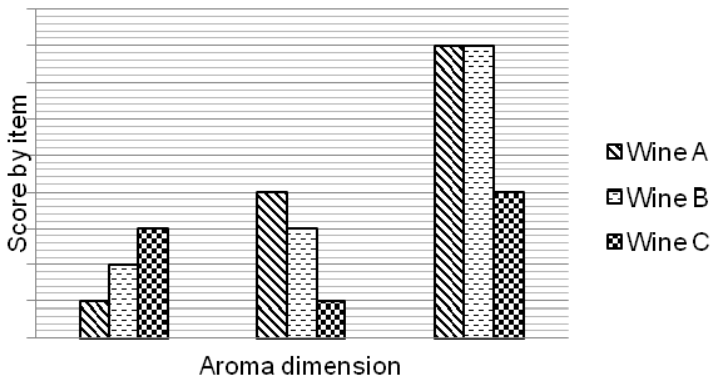

Figure 1. Quality analysis of three wines. Aroma dimension.

Dimensão olfato para a análise de qualidade de três vinhos.

Under this simulated situation, if the assignment of an award to the wine depends only on this aspect, certainly the assignment of that award will be different, which is definitely the origin of the proposed methodology.

Currently, the use of technology has allowed the development of a series of strategic methodologies for the analysis of score sheets; for example, applying the response theory to the item, and the incorporation of the time of the response (Cabrera et al., 2010), which has allowed to capture the dynamic of the interactions in the most precise way and free from individual bias.

For this reason, the aim of this paper is to propose an analysis and visualization methodology of the dynamic of the assigning of awards to a wine, proposing a new concept of awards.

The specific objectives of the research are:

- To promote a visualization method and stochastic quantification of the dynamic of the scoring of a tasting score sheet.

- To describe and characterize the graphs of consistency of the awards for wine (GCAW).

- To present an initial theoretical structure for the dynamic of the scoring of the tasting score sheet.

- To present a methodology that formalizes confidence intervals for the consistency of the award.

- $\quad$ To promote a line of research with respect to the GCAW.

\section{MATERIALS AND METHODS}

The methodology of this study is exploratory, which attempts to set the theoretical basis, suppositions and restrictions of the methodology for the analysis of wine awards, and its consistency graphs.

The description of the fundamental concepts that support the methodology are given below:

1. Graph and its restrictions: A graph $G$ is a pair $(V$, $\mathrm{E}$ ) where $\mathrm{V}$ is a finite, non-empty group of objects called vertices, and $\mathrm{E}$ is a group (possibly empty) of non-ordered pairs of distinct vertices of $G$ called edges or lines. The group of vertices of $G$ is denoted by $V(G)$, while the group of edges or lines is denoted by $\mathrm{E}(\mathrm{G})$. If $e=\{u, v\}$ is a border or a line of graph $\mathrm{G}$, then $u$ and $v$ are adjacent vertices, while $u$ and $e$ are incidents, as are $v$ and $e$. Furthermore, if $\mathrm{e}_{1}$ and $\mathrm{e}_{2}$ are edges distinct from $G$ incidents with a common vertex, then $e_{1}$ and $e_{2}$ are adjacent edges. From here forward, a line will be denoted by $u v$ or $v u$ instead of $\{u, v\}$.

The cardinality of the group of vertices of graph $G$ is called the order of $\mathrm{G}$, and is denoted by $p(G)$, or more simply $p$, and the cardinality of the group of edges is the size of $\mathrm{G}$ and is denoted by $q(G)$ or $q$. A graph $(p, q)$ has order $p$ and size $q$.

It is customary to define or describe a graph by means of a diagram in which each vertex is represented by a point and each edge $e=u v$ is represented by a segment of the line or curve that unites the points that correspond to $u$ and $v$.

A graph $\mathrm{G}$, with a group of vertices $V(G)=$ $\left\{v_{1}, v_{2}, \ldots, v_{\mathrm{p}}\right\}$ can also be described by means of matrices. Thus $A(G)=\left[a_{i j}\right]$, where:

$a_{i j}=\left\{\begin{array}{l}1 \text { if } v_{i} v_{j} \in E(G) \\ 0 \text { if } v_{i} v_{j} \notin E(G)\end{array}\right.$

which is called the matrix of adjacency of Graph G.

Another way of representing a graph is through the matrix of incidence. Thus $B(G)=\left[b_{i j}\right]$, where:

$b_{i j}=\left\{\begin{array}{c}1 \text { if } v_{i} \text { and } e_{j} \text { are incidents } \\ 0 \text { if } v_{i} \text { and } e_{j} \text { are not incidents }\end{array}\right.$

Another concept to point out in the theory of graphs is the degree of a vertex $v$ in a graph $G$, which is the number of edges of $G$ incident with $v$. The degree of a vertex $v$ in $G$ is denoted $\operatorname{deg}_{G} v$ or simply degv, which in this paper will be represented by $X$. A vertex is called even or odd if the degree is even or odd. A vertex of degree 0 in $G$ is called an isolated vertex and a vertex of degree 1 is a final vertex of $G$.

Complete Graph: For a number of vertices $n$, with $n \geq 1$, the maximum number of edges or lines that can be defined is $\frac{n(n-1)}{2}$, which characterizes the complete graph, designated by $K_{n}$ (Montenegro et al., 2010). 
2. Poisson model and its asymptotics (Shao, 2003): If $X$ is a random variable, defined as the number of events that occur per unit of time (space, volume, among others), then it is proven that under certain suppositions:

$I P(X=x)=\frac{e^{-\lambda} \lambda^{x}}{x !} ; x=0,1,2, \ldots$

denominated the quantity function or probability mass. A random variable of this type is completely characterized; definitely, if $X$ is a random variable whose distribution is Poisson of parameter $\lambda$, it will be written as: $X \sim P(\lambda)$.

On the other hand, from the inferential point of view, if $X_{1}, X_{2}, \ldots, X_{n}$ is a random sample from a population that is supposed to have the function of quantity or probability mass

$I P(X=x)=\frac{e^{-\lambda} \lambda^{x}}{x !} ; x=0,1,2, \ldots$

then the most likely estimator of the parameter $\lambda$ is $\hat{\lambda}=\bar{X}$, which as a consequence of the central theorem of limits, has an asymptotic distribution of: $\hat{\lambda}=\overline{\mathrm{X}} \sim \mathrm{N}(\mathrm{E}(\overline{\mathrm{X}}), \operatorname{Var}(\overline{\mathrm{X}}))$,

that is to say

$\hat{\lambda}=\bar{X} \sim N\left(\lambda, \frac{\lambda}{n}\right)$,

on the basis of which the following pivot is defined:

$\frac{(\bar{X}-\lambda) \sqrt{n}}{\lambda}$

whose distribution is standard normal, that is to say:

$\frac{(\bar{X}-\lambda) \sqrt{n}}{\lambda} \sim \mathrm{N}(0,1)$

Then a confidence interval for $\lambda$ of $(1-\alpha) 100 \%$ is:

$$
\left[\frac{\bar{X} \sqrt{n}}{\sqrt{n}+Z_{1-\frac{\alpha}{2}}} ; \frac{\bar{X} \sqrt{n}}{\sqrt{n}-Z_{1-\frac{\alpha}{2}}}\right]
$$

Let $M$ be a matrix of responses of the order $p x n$, where $p$ represents the number of items in the score sheet, which is assumed to possess good metric characteristics; and $n$ the number of specialists that participate in the assignment of the award for a wine, because of which each column is composed of the numeric quantification of the scores assigned by each specialist for each item of the score sheet.

Afterwards, the scores assigned by each specialist will be analyzed by means of the tasting score sheet, and studied with respect to the similarity or cohesion with the ideas of their peers on the same score sheet; this will be quantified with the Pearson coefficient of correlation (Schervish, 1995). In this way, a square matrix is generated on the order $n,\left[\rho_{i j}\right]$, where $\rho_{i j}$ represents the correlation between the scores given by the $i$-th specialist and those given by the $j$-th specialist on the score sheet. On the basis of the correlation matrix, $\left[\rho_{i j}\right]$, the matrix of consistency is defined,

which is a variation of the former in which the $\rho_{i i}$ are considered to be equal to zero, which will be called $C=\left[C_{i j}\right]$.

$$
C=\left[c_{i j}\right] \text { is a symmetric matrix, whose }
$$
components of the principal diagonal are zeroes.

Among the coefficients of the matrix of consistency, all those that represent a significant dependency are interesting; for example: $\left|c_{i j}\right| \geq 0,5$.

The value 0.5 is an example that depends on the interest in the power of the correlation or linear dependence. The notation absolute value was used because the interest was to discover the existence of interaction between responses, direct or indirect.

Other method is based on the usage of statistical techniques. That is, to study whether the correlation is significant using the t-student distribution (See Casella, 2005).

Let $C=\left[C_{i j}\right]$ be a matrix of consistency and $A=\left[a_{i j}\right]$ the matrix of adjacency,

$$
a_{i j}=\left\{\begin{array}{l}
0 \text { if }\left|c_{i j}\right|<q \\
1 i f\left|c_{i j}\right| \geq q
\end{array}\right.
$$

where $q$ is the cutoff threshold; then, if $a_{i j}=0$, there is no link or consistency between specialist $i$ and specialist $j$; if $a_{i j}=1$, then there is a link or consistency between the award of specialist $i$ and that of specialist $j$.

3. The graph of consistency of awards for a wine (GCAW), is one in where its vertices are the specialists that were part of the process of assignment of awards by means of the score sheet, and the edges or lines represent the existence of consistent awards among the specialists involved, which will be seen if $a_{i j}=1$.

4. Degree: the degree of a vertex $v$ of a graph of consistency of awards for a wine, is the number of edges or lines of the GCAW incident with $v$, which is represented as $X$.

Under this concept, the degree of a vertex $v$ or simply $X$, is a random variable of count and the best model to this type of specifications is Poisson distribution, since the number of incident edges in vertex $v$ is counted, and therefore is a discrete model. This is what we will call a stochastic model for the quantification of the consistency of the awards for a wine, which in this case is represented by $\lambda$. Based on 
the Central Limit Theorem, this states that independent from the type of random variable that is discrete or continuous, the mean of this random sample is asymptotically normally distributed. This allows to define a pivot.

That is to say,

$X \sim P(\lambda)$

so

$$
\hat{\lambda}=\overline{\mathrm{X}} \sim \mathrm{N}(\mathrm{E}(\overline{\mathrm{X}}), \operatorname{Var}(\overline{\mathrm{X}})),
$$

and that is to say

$\hat{\lambda}=\bar{X} \sim N\left(\lambda, \frac{\lambda}{n}\right)$

on the basis of which the following pivot is defined:

$$
\frac{(\bar{X}-\lambda) \sqrt{n}}{\lambda}
$$

whose distribution is standard normal, that is to say:

$$
\frac{(\bar{X}-\lambda) \sqrt{n}}{\lambda} \sim \mathrm{N}(0,1) \text {. }
$$

So a confidence interval for $\lambda$ of $(1-\alpha) 100 \%$ is:

$$
\left[\frac{\bar{X} \sqrt{n}}{\sqrt{n}+Z_{1-\frac{\alpha}{2}}} ; \frac{\bar{X} \sqrt{n}}{\sqrt{n}-Z_{1-\frac{\alpha}{2}}}\right] .
$$

This degree characterizes the group of specialists in a quantified way, with respect to the consistency of the awards assigned, besides allowing contrast with other groups.

\section{RESULTS AND DISCUSSION}

A matrix of the assignation of scores will be simulated by means of the tasting score sheet on the order of $10 \times 30$, where 10 is the number of items of the score sheet identified by the rows, and 30 the number of specialists that were part of the process of awards, represented in the columns.

Then, the described methodology was applied, obtaining Table II, which represents the existence or absence of consistency among the opinions of each of the specialists, being numbered with 1 or 0 , respectively.

\begin{tabular}{|c|c|c|c|c|c|c|c|c|c|c|c|c|c|c|c|c|c|c|c|c|c|c|c|c|c|c|c|c|c|c|}
\hline & Fer1 & Fer 2 & Fers & Pers & Fer: & FerG & Peri & Fers & Fers & Pert & Fer11 & Fer12 & PFer13 & Per14 & 4 Per1s & Per1E & Fer17 & Per18 & Fer 19 & Fer2 & dPerz1 & Fer 22 & Fer23 & Fer 2 & $4 \mathrm{Fer} 25$ & Fer2a & Fer27 & Fer 2 & Aper2s & Per30 \\
\hline Fer1 & 0 & 1 & 0 & 0 & 0 & 1 & 0 & 0 & 0 & 0 & 0 & 0 & 0 & 0 & 0 & 0 & 0 & 0 & 0 & 0 & 0 & 1 & 0 & 0 & 0 & 0 & 0 & 0 & 1 & 0 \\
\hline Fer2 & 1 & $\overline{0}$ & 0 & 0 & $\overline{0}$ & 0 & 0 & 0 & 0 & 0 & 0 & 0 & 0 & 0 & 0 & 0 & 0 & 0 & 0 & 0 & 0 & 0 & 0 & 0 & 0 & 0 & 1 & 0 & 0 & 0 \\
\hline Fers & 0 & 0 & 0 & 0 & 0 & 0 & 0 & 0 & 1 & 0 & 0 & 1 & 0 & 0 & 1 & 0 & 0 & 1 & 0 & 0 & 0 & 0 & 0 & 0 & 0 & 1 & 0 & 0 & 0 & 0 \\
\hline Per4 & $\underline{0}$ & 0 & 0 & 0 & 0 & 0 & 0 & 1 & 0 & 0 & 1 & 0 & 0 & 0 & 0 & 0 & 0 & 1 & 0 & 0 & 0 & 0 & 1 & 0 & 0 & 1 & 0 & 0 & 0 & 0 \\
\hline Pers & 0 & 0 & 0 & 0 & 0 & 1 & 0 & 1 & 0 & 0 & 0 & 1 & 0 & 0 & 0 & 0 & 0 & 0 & 1 & 0 & 0 & 0 & 0 & 0 & 0 & 0 & 0 & 1 & 0 & 0 \\
\hline Pers & 1 & $\underline{0}$ & 0 & 0 & 1 & 0 & $\underline{0}$ & 0 & 0 & $\underline{0}$ & 0 & $\underline{0}$ & 0 & 0 & 1 & 1 & 0 & 0 & 0 & $\underline{0}$ & 0 & 0 & 0 & 0 & 0 & 0 & 0 & 0 & 0 & 0 \\
\hline Perf & 0 & 0 & 0 & 0 & $\underline{0}$ & 0 & 0 & 0 & 1 & 0 & 1 & 0 & 1 & 0 & 0 & 0 & 0 & 0 & 0 & 0 & 0 & 0 & 0 & 0 & 0 & 0 & 0 & 0 & 0 & $\underline{0}$ \\
\hline Fer8 & 0 & 0 & 0 & 1 & 1 & 0 & 0 & 0 & 0 & 0 & 0 & 0 & 0 & 0 & 0 & 0 & 0 & 1 & 1 & 0 & 0 & 0 & 0 & 0 & 0 & 0 & 0 & 0 & 0 & 0 \\
\hline Fers & 0 & 0 & 1 & 0 & $\underline{0}$ & 0 & 1 & 0 & 0 & 0 & 0 & 1 & 0 & 0 & 1 & 0 & 0 & 0 & 0 & 1 & 0 & 0 & 0 & 0 & 0 & 0 & 0 & 0 & 0 & 0 \\
\hline Fer10 & 0 & 0 & 0 & 0 & 0 & 0 & 0 & 0 & 0 & 0 & 0 & 0 & 1 & 0 & 0 & 0 & 0 & 0 & 1 & 0 & 0 & 0 & 0 & 0 & 0 & 1 & 0 & 0 & 0 & 0 \\
\hline Fer11 & 0 & 0 & 0 & 1 & 0 & 0 & 1 & 0 & 0 & 0 & 0 & 0 & 0 & 0 & 0 & 0 & 0 & 0 & 0 & 1 & 0 & 0 & 1 & 0 & 0 & 0 & 0 & 0 & 0 & 0 \\
\hline Fer12 & 0 & 0 & 1 & 0 & 1 & 0 & 0 & 0 & 1 & 0 & 0 & 0 & 0 & 0 & 1 & 0 & 0 & 0 & 0 & 0 & 0 & 1 & 0 & 0 & 0 & 0 & 0 & 0 & 0 & 1 \\
\hline Fer13 & 0 & 0 & 0 & 0 & 0 & 0 & 1 & 0 & 0 & 1 & 0 & 0 & 0 & 0 & 0 & 0 & 0 & 0 & 0 & 0 & 0 & 0 & 0 & 0 & 0 & 0 & 0 & 0 & 0 & 0 \\
\hline Per14 & 0 & 0 & 0 & 0 & 0 & 0 & 0 & 0 & 0 & 0 & 0 & 0 & 0 & 0 & 0 & 0 & 0 & 0 & 1 & 0 & 0 & 0 & 0 & 1 & 1 & 0 & 0 & 0 & 0 & 0 \\
\hline Per1s & 0 & 0 & 1 & 0 & 0 & 1 & 0 & 0 & 1 & 0 & 0 & 1 & 0 & 0 & 0 & 1 & 0 & 0 & 0 & 0 & 0 & 0 & 0 & 0 & 0 & 0 & 0 & 0 & 0 & 0 \\
\hline P'er16 & 0 & 0 & 0 & 0 & 0 & 1 & 0 & 0 & 0 & 0 & 0 & 0 & 0 & 0 & 1 & 0 & 0 & 0 & 0 & 0 & 0 & 0 & 0 & 0 & 0 & 0 & 0 & 0 & 0 & 0 \\
\hline Per17 & 0 & 0 & 0 & 0 & 0 & 0 & 0 & 0 & 0 & 0 & 0 & 0 & 0 & 0 & 0 & 0 & 0 & 0 & 0 & 0 & 0 & 1 & 0 & 0 & 0 & 0 & 1 & 0 & 0 & 0 \\
\hline Fer18 & 0 & 0 & 1 & 1 & 0 & 0 & 0 & 1 & 0 & 0 & 0 & 0 & 0 & 0 & 0 & 0 & 0 & 0 & 0 & 0 & 0 & 0 & 0 & 0 & 0 & 1 & 0 & 0 & 0 & 0 \\
\hline Fer19 & 0 & 0 & 0 & 0 & 1 & 0 & 0 & 1 & 0 & 1 & 0 & 0 & 0 & 1 & 0 & 0 & 0 & 0 & 0 & 0 & 0 & 0 & 0 & 1 & 0 & 0 & 0 & 0 & 0 & 0 \\
\hline Fer20 & 0 & 0 & 0 & 0 & 0 & 0 & 0 & 0 & 1 & 0 & 1 & 0 & 0 & 0 & 0 & 0 & 0 & 0 & 0 & 0 & 1 & 0 & 0 & 1 & 0 & 0 & 0 & 0 & 1 & $\overline{0}$ \\
\hline Ferz1 & 0 & 0 & 0 & 0 & 0 & 0 & 0 & 0 & 0 & 0 & 0 & 0 & 0 & 0 & 0 & 0 & 0 & 0 & 0 & 1 & 0 & 0 & 0 & 1 & 0 & 0 & 0 & 0 & 1 & 0 \\
\hline Fer2 & 1 & 0 & 0 & 0 & 0 & 0 & 0 & 0 & 0 & 0 & 0 & 1 & 0 & 0 & 0 & 0 & 1 & 0 & 0 & 0 & 0 & 0 & 0 & 0 & 0 & 0 & 0 & 0 & 0 & 0 \\
\hline P'er23 & 0 & 0 & 0 & 1 & 0 & 0 & 0 & 0 & 0 & 0 & 1 & 0 & 0 & 0 & 0 & 0 & 0 & 0 & 0 & 0 & 0 & 0 & 0 & 0 & 0 & 0 & 0 & 0 & 0 & 1 \\
\hline P'er24 & 0 & 0 & 0 & 0 & 0 & 0 & 0 & 0 & 0 & 0 & 0 & 0 & 0 & 1 & 0 & 0 & 0 & 0 & 1 & 1 & 1 & 0 & 0 & 0 & 1 & 0 & 0 & 0 & 1 & 0 \\
\hline Pers & 0 & 0 & 0 & 0 & 0 & 0 & 0 & 0 & 0 & $\underline{0}$ & 0 & 0 & 0 & 1 & 0 & 0 & 0 & 0 & 0 & 0 & 0 & 0 & 0 & 1 & 0 & 0 & 0 & 0 & 1 & 0 \\
\hline Per26 & 0 & 0 & 1 & 1 & 0 & 0 & 0 & 0 & 0 & 1 & 0 & 0 & 0 & 0 & 0 & 0 & 0 & 1 & 0 & 0 & 0 & 0 & 0 & 0 & 0 & 0 & 1 & 0 & 0 & 0 \\
\hline Fer27 & 0 & 1 & 0 & 0 & 0 & 0 & 0 & 0 & 0 & 0 & 0 & 0 & 0 & 0 & 0 & 0 & 1 & 0 & 0 & 0 & 0 & 0 & 0 & 0 & 0 & 1 & 0 & 0 & 0 & 0 \\
\hline Fer28 & 0 & 0 & 0 & 0 & 1 & 0 & 0 & 0 & 0 & 0 & 0 & 0 & 0 & 0 & 0 & 0 & 0 & 0 & 0 & 0 & 0 & 0 & 0 & 0 & 0 & 0 & 0 & 0 & 0 & 0 \\
\hline Fer2a & 1 & 0 & 0 & 0 & 0 & 0 & 0 & 0 & 0 & 0 & 0 & 0 & 0 & 0 & 0 & 0 & 0 & 0 & 0 & 1 & 1 & 0 & 0 & 1 & 1 & 0 & 0 & 0 & 0 & 0 \\
\hline Fer30 & 0 & 0 & 0 & 0 & $\underline{0}$ & 0 & $\underline{0}$ & 0 & 0 & 0 & 0 & 1 & 0 & 0 & 0 & 0 & 0 & 0 & 0 & 0 & 0 & 0 & 1 & 0 & 0 & 0 & 0 & 0 & 0 & $\underline{0}$ \\
\hline
\end{tabular}

TABLE II

Consistency between specialists views in wine analysis

Consistência entre as opiniões dos especialistas na análise do vinho

In order to represent the GCAW, it is necessary to identify that the components of the matrix of adjacency (Table II) are equal to 1, i.e., $a_{i j}=1$, on the basis of which Figure 2 results.
It can be observed that to the extent that the GCAW converges to complete graph, the consistency of the awards increases. On the other hand, the degree of the vertices of the graph of conceptual consistency, $X$, has 
the distribution of frequencies that can be seen in Figure 3.

This distribution is modeled by the Poisson distribution, which on using the asymptotic properties of the estimators of $\lambda$ quantifies the consistency of the awards by means of the following interval:

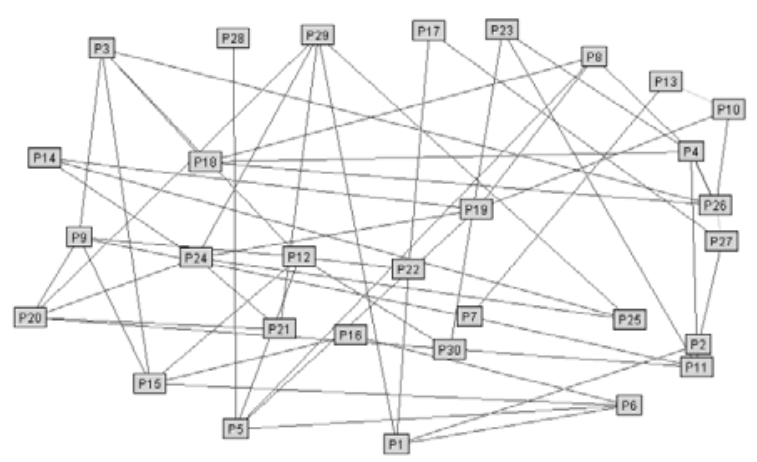

Figure 2. Consistency graph of a wine reward.

Grafo de consistência da recompensa do vinho.

Considering $\alpha=0,05$, it has:

$$
\left[\frac{3.73 \sqrt{30}}{\sqrt{30}+Z_{1-\frac{\alpha}{2}}} ; \frac{3.73 \sqrt{30}}{\sqrt{30}-Z_{1-\frac{\alpha}{2}}}\right]
$$

where $Z_{1-\frac{0.05}{2}}=Z_{0.975}=1,96$, thus

$$
\left[\frac{3.73 \sqrt{30}}{\sqrt{30}+Z_{1-\frac{\alpha}{2}}} ; \frac{3.73 \sqrt{30}}{\sqrt{30}-Z_{1-\frac{\alpha}{2}}}\right]=\left[\frac{3.73 \sqrt{30}}{\sqrt{30}+1.96} ; \frac{3.73 \sqrt{30}}{\sqrt{30}-1.96}\right]=\left[\frac{20.43}{7.437} ; \frac{20.43}{3.517}\right]=[2.74 ; 5.80]
$$

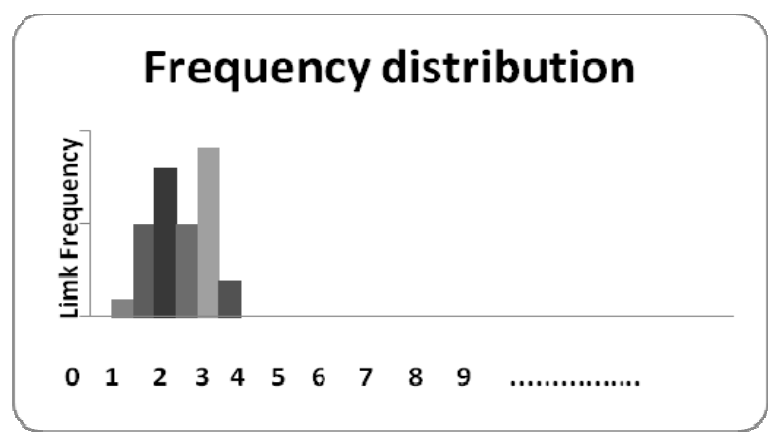

Figure 3. Frequency distribution of consistent links.

Distribuição de frequências dos vínculos consistentes.

This interval quantitatively characterizes the group of specialists and their award values, translating them into consistency and allowing contrast with other groups.

In a similar way, another tasting score sheet was simulated, for which the GCAW is represented in Figure 4.

The difference between the two groups can be observed in Figure 4, where the number of connections or edges is greater and the convergence of the complete graph is clearer. Therefore, this wine has an award of greater consistency than the one shown in Figure 2.

In the same way, using $\alpha=0,05$, it can be seen that the degree of consistency of awards is:

$\left[\frac{6.87 \sqrt{30}}{\sqrt{30}+Z_{1-\frac{\alpha}{2}}} ; \frac{6.87 \sqrt{30}}{\sqrt{30}-Z_{1-\frac{\alpha}{2}}}\right]$

where $Z_{1-\frac{0.05}{2}}=Z_{0.975}=1,96$, thus

$\left[\frac{6.87 \sqrt{30}}{\sqrt{30}+Z_{1-\frac{\alpha}{2}}} ; \frac{6.87 \sqrt{30}}{\sqrt{30}-Z_{1-\frac{\alpha}{2}}}\right]=\left[\frac{6.87 \sqrt{30}}{\sqrt{30}+1.96} ; \frac{6.87 \sqrt{30}}{\sqrt{30}-1.96}\right]=\left[\frac{37.62}{7.437} ; \frac{37.62}{3.517}\right]=[5,05 ; 10.7]$

hence, it may be emphasized that the quantification of the second group of specialists allows to define a larger degree, and therefore, a greater bound; this means that the dynamic of the links of this group is greater than the former group, translating to a wine whose awards are more consistent.

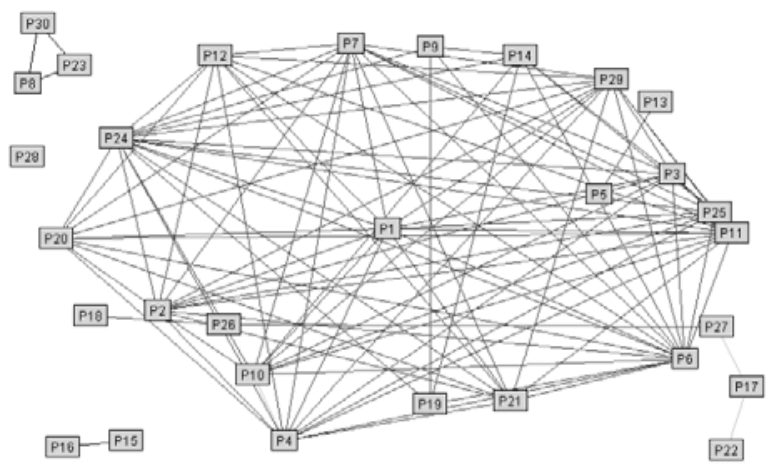

Figure 4. Consistency graph of another wine reward.

Grafo de consistência da recompensa de outro vinho.

On the other hand, in spite of having greater consistency among the awards, in the second group, the visualization of the theory of graphs shows the existence of totally atypical opinions, which is important from the determination of the award point of view, even more if this behavior has relevant influence on the definitive assignment of the award.

\section{CONCLUSIONS}

This proposal represents an advance in the application of statistical and mathematical techniques to the awards for a wine, defining a new concept of quality called consistent award.

The stochastic quantification allows incorporating dependence and statistical equivalencies, which facilitates the comparison of detection of links or atypical situations in the process of the assignation of awards. 
The visualization that graph theory allows, is definitely a powerful statistical tool, giving shape in the second group modeled (Figure 4), which allows to observe atypical situations or disjointed groups; this, is of utmost importance from the point of view of the assignation of consistent awards. The proposal that has been developed here opens a line of research and development that benefits the characterization of the dynamic of the scores assigned by means of the tasting score sheet. In this first step, the basis of a formal language is structured in which stochastic processes and deterministic developments interact, allowing a visualization of that dynamic and defining a theoretical support for consistent awards.

On the other hand, it is probable that under the traditional method of determination of awards for a wine, both groups have the same score; nevertheless, the actual study of the internal dynamics of the scores by means of the tasting score sheet allows a refinement of the award, translated into consistency. These new values for consistent awards in the evaluation of the quality of wines are: Grand Gold (Consistent or Inconsistent), Gold (Consistent or Inconsistent), Silver (Consistent or Inconsistent) and Bronze (Consistent or Inconsistent).

Currently, we are working on generating a software that implements the method. In the future, it will be applied in real situations for calibration, and finally, this will be released to the public.

\section{ACKNOWLEDGMENTS}

The authors acknowledge the support of the Experimental Laboratory of Mathematical Knowledge, LAB[E]SAM and the Laboratory Data Analysis and Statistical Knowledge, LADYSE, University of Playa Ancha. The Coordination of Improvement of Higher Education Personnel, CAPES. State University of Campinas, UNICAMP, IMECC. The Department of Civil and Agricultural Engineering. School of Engineering - National University of Colombia.

\section{REFERENCES}

Alvelos H., Cabral J. A., Amaral B., Barros P., 2000. Statistical Methods for Controlling Wine Tasting Panels. Ciência Téc. Vitiv., 15, 15-26.

Bi J., 2003. Agreement and reliability assessments for performance of sensory descriptive panel. J. Sens. Stud., 18, 61-76.

Brien C.J., May P., Mayo O., 1987. Analysis of judge performance in wine quality evaluations. J. Food Sci., 52, 1273-1279.

Cabrera E., Gonzalez J., Montenegro E., 2010. Test informatizados y el registro del tiempo de respuesta, una vía para la precisión en la determinación del nivel de logro de un saber matemático. Estud. Pedagóg., 36, 69-84.
Cardinal M., Cornet J., Qannari A., Qannari M., 1994. Performances d'um Groupe d'Évaluation Sensorielle: Exemples de Traitements Statistiques des Données. Sci. Aliments, 14, 251-263.

Etaio I., Albisu M., Ojeda M., Gil P.F., Salmerón J., Pérez Elortondo F.J., 2010. Sensory quality control for food certification: a case study on wine. Food Control, 21, 533-542.

Gawel R., Godden P., 2008. Evaluation of the consistency of wine quality assessments from expert wine tasters. Australian J. Grape and Wine Res., 14, 1-8.

Gawel R., Oberholster A., Francis I.L., 2000. A 'Mouth-feel Wheel': terminology for communicating the mouth-feel characteristics of red wine. Australian J. Grape Wine Res., 6, 203207.

Gladstones J.S., 2011. Wine, terroir and climate change. Wakefield Press, Kent Town.

Jackson, R.S., 2009. Wine tasting: a professional handbook. Academic Press.

King M.C., Hall J., Cliff M.A., 2001. A comparison of methods for evaluating the performance of a trained sensory panel. J. Sens. Stud., 16, 567-581.

Latreille J., Mauger E., Ambroisine L., Tenenhaus M., Vincent M., Navarro S., Guinot C., 2006. Measurement of the reliability of sensory panel performances. Food Qual. and Preference, 17, 369375 .

Lawless H., Liu Y.-F., 1997. Evaluation of wine quality using a small-panel hedonic scaling method. J. Sens. Stud., 12, 317-332.

Lima L.B., Belchior A.P., Estabrook G.F., 1988. Uniformity and constancy of wine tasters evaluating the same wine on two different occasions. Ciência Téc. Vitiv. 7, 73-85.

Manfroi V., Costa G.P., Guerra C.C., Zanus M.C., Fialho F.B., Rombaldi C.V., 2010. Aplicação de taninos enológicos na elaboração de vinho Cabernet Sauvignon e seus efeitos sobre a qualidade sensorial. Ciência Rural, 40, 175-181.

Montenegro E., González J., Cabrera E., 2010. Graphs r-polar Spherical Realization. Proyecciones (Antofagasta), 29, 31-39.

Muroz A.M., Civille G.V., Carr B.T., 1992. Sensory Evaluation in Quality Control. Chapman \& Hall, New York.

Noble A.C., Arnold R.A., Buechsenstein J., Leach E.J., Schmidt J.O., Stern P.M., 1987. Modification of a standardized system of wine aroma terminology. Am J. Enol. Vitic., 38, 143-146.

OIV. Norma OIV de los Concursos Internacionales de Vinos y Bebidas Espirituosas de Origen Vitivinícola. Resolución OIV/CONCOURS 332A/2009. Retrieved from: http://www.oiv.int/oiv/info/esconcours. [Accessed in $15^{\text {th }}$ September 2011].

Rizzon L.A., Miele A., Menuguzzo J., Zanuz M.C., 1999. Efeito de três processos de vinificação sobre a composição química e a qualidade do vinho cabernet franc. Pesq. agropec. bras., 34, 12851293.

Schervish M., 1995.Theory of Statistics. Springer, New York.

Shao J., 2003. Mathematical Statistics. Second Edition. Springer, New York.

Sinesio F., Risvik E., Rodbotten M., 1990. Evaluation of Panelist Performance in Descriptive Profiling of Rancid Sausages: a Multivariate Study. J. Sensory Studies, 5, 33-52.

Vannier A., Brun O.X., Feinberg M.H., 1999. Application of sensory analysis to Champagne wine characterization and discrimination. Food Qual. and Preference, 10, 101-107. 